\title{
Cal Poly's Sustainability Program: What is Its Effect on Students?
}

\author{
Daniel Levi \\ PhD.; professor, Psychology and Child \\ Development Department, Cal Poly.
}

\author{
Rebecca Sokoloski \\ Graduate student at CSU San Marco. At the \\ time of this article, she was a senior in Cal Poly's \\ Psychology Child Development Department.
}

Cal Poly has been promoting sustainability directly through campus planning and the design of its new facilities, and indirectly through curriculum changes and a series of events and on-going activities to raise consciousness. In this article, Daniel Levi and Rebecca Sokoloski ask themselves if Cal Poly has been successful and discuss their studies on the meaning, attitudes, sustainable behaviors, and social norms regarding sustainability among students.

$C^{2}$ Poly has been working for nearly a decade to improve sustainability on campus, utilizing a variety of approaches. It is important to assess the effects of the University's sustainability program on the knowledge, attitudes, behavior and social norms of students.

Sustainable development is "development that meets the needs of the present without compromising the ability of future generations to meet their own needs" (UN Commission on Environment and Development, 1987). Sustainability creates the potential for long-term maintenance of human well-being, which has environmental, economic, and social dimensions. With environmental problems threatening our economic and social well-being, a change to sustainability has to be seen as desirable, as creating a better future. This change will not occur by threatening people with ecological doom, but by promoting positive attitudes toward sustainability (Porritt, 2005).

Since 2004, Cal Poly has been a signatory of the Tallories Declaration, which is a ten-point plan to promote sustainability and environmental literacy in teaching, theory, and practice at universities. The plan's components include increasing awareness of sustainable development, educating for environmentally responsible behavior, fostering environmental literacy, and practicing institutional ecology.

The University has developed a set of Sustainability Learning Objectives for students. Cal Poly students should be able to: "1. Define and apply sustainability principles within their academic programs; 2. Explain how natural, economic, and social systems interact to foster and prevent sustainability; 3 . Analyze and explain local, national, and global sustainability using a multidisciplinary approach; and 4. Consider sustainability principles while developing personal and professional values." (Cal Poly, 2013).

We wish to thank the following students for their help with this research: Lacey Buck, Victoria Carranza, Amanda Purser, and Cassandra Walker.
Cal Poly has undertaken a variety of actions to promote sustainability on campus. The management of the campus's physical environment has undergone major changes to improve sustainability, with expanded recycling and water conservation programs, energy and resource use audits, solar panels, and LEED-certified new buildings. There are over 100 courses offered at Cal Poly that address sustainability issues, and 12 University minors focus on sustainability, including the Sustainable Environments Minor in the School of Architecture.

Students are not currently required to take a sustainability class (although this is under consideration by the University); however, sustainability awareness is encouraged in other ways. The Green Campus Program works with student clubs, such as the Empower Poly Coalition, to promote sustainability knowledge and practices among students. Sustainability education and awareness programs are part of freshmen orientation. Programs in the dorms promote awareness of sustainability issues on campus, such as water use, transportation, energy use, and recycling. Sustainable behaviors are encouraged through programs such as the Red Brick Energy Competition among the dorms.

Cal Poly's efforts to promote sustainability have received a number of awards. In 2012 alone, Cal Poly received Best Practice Awards for Water Efficiency, Innovative Sustainability Mentor Program, and Student Sustainability Program by the California Higher Education Sustainability Conference (Cal Poly, 2013).

\section{Assessing Student Sustainability}

Cal Poly has a goal of promoting sustainability. Part of this goal is to encourage the students to become more knowledgeable about sustainability issues and to act in a more sustainable manner. How does a university promote sustainability among its students? Should the focus be on increasing knowledge about sustainability or promoting sustainable behaviors, or 
both? What are the appropriate measures to evaluate whether Cal Poly is successful? These are questions facing the University.

As a university, it is obviously important that Cal Poly focuses on teaching students about sustainability. Cal Poly's Sustainability Learning Objectives focus on the development of knowledge about sustainability and its application. Knowledge about sustainability is a necessary but not sufficient condition for encouraging sustainable behaviors. Research shows that there is a weak link connecting sustainability knowledge with attitudes and behaviors (Gifford, 2007). This is why university programs also need to focus on changing students' attitudes and behaviors toward sustainability, not just on imparting knowledge.

Environmental psychologists have examined the relationship between knowledge, attitudes, and behavior about sustainability (Gifford, 2007). In addition to awareness and knowledge, performing sustainable behaviors relates to attitudes about sustainability, behavioral control (or how difficult the behavior is to perform), and social norms (the attitudes and behaviors of important people in one's life) (Ajzen, 1991). For university students, social norms come from one's family, friends or peers, and professors.

Descriptive social norms guide ones behavior based off of what most people do (Cialdini, 1991). The more salient a norm is, the more it calls for the individual to make social comparisons between themselves and perceived norms. Although social norms do not directly and immediately change an individual's attitudes on sustainability, they can be used to influence the individual's behavior. In particular, an individual's friends and family's behavior can heavily influence the person's own behavior (Nickerson, 2002). Descriptive norms are particularly apparent on college campuses.

The University has undertaken a variety of actions to improve its ecological footprint and to promote sustainability among the students. It is important to assess how well the University is performing in order to provide feedback to improve. The changes in the University's physical operations are regularly monitored and assessed. The University has identified the need to develop a better assessment system for examining whether it is meeting its Sustainability Learning Objectives. Our research was conducted to help examine some approaches to doing this and to see how well Cal Poly is doing promoting sustainability among the students.

\section{Methods}

In order to assess Cal Poly students' knowledge, attitudes, and behaviors toward sustainability, Dr. Levi and his students have conducted several studies. These studies have been part of class projects in the Environmental Psychology class and Rebecca Sokoloski's senior project. The first study examined knowledge about sustainability with the open-ended question, "What does sustainability mean to you?" It also pretested an attitude rating scale about the impact of sustainability on self and society. Over 140 students from General Education (GE) classes and the dorms participated in the study. In the second study, which was a senior project, over 100 students from GE classes completed a survey on sustainability attitudes, behaviors, and social norms. In both studies, the sample included students from a variety of majors and class levels.

\section{Results}

Knowledge about sustainability was examined from the responses to the question, "What does sustainability mean to you?"Two judges classified the responses into six issues related to sustainability. A response could relate to more than one topic. Although most students emphasized the conservation of energy and resources and concern about the future, only a minority of students recognized the economic and social implications of sustainability. (See Table 1 for the results)

Table 1: Meaning of Sustainability (Percent).

\begin{tabular}{|l|c|}
\hline Energy conservation and resource use & $63 \%$ \\
\hline Concern about future generations & $32 \%$ \\
\hline Sustainable economics and social justice & $21 \%$ \\
\hline Protection of natural areas and wildlife & $18 \%$ \\
\hline Reducing pollution & $15 \%$ \\
\hline Managing human population growth & $7 \%$ \\
\hline
\end{tabular}

The attitude survey asked the students to consider the impacts of our society's shift toward sustainability on their personal life, society and the world. Attitudes toward sustainability were measured on a five-point scale from very negative to very positive. Table 2 presents the percent of positive responses (a 4 or 5 rating). Overall, the students had positive attitudes toward sustainability. They were more positive about the effects of sustainability on society and the world than the personal impacts of sustainability.

Students also rated how often they engage in sustainable behaviors. The selection of behaviors was designed to be available to Cal Poly students, including those living on campus. Table 3 presents the results for the behaviors that students usually or always perform (which were 4 and 5 on a five-point scale that ranged from never to always). As can be seen from the table, the frequency of behaviors varied substantially among the topics. Students were good at doing laundry with full loads, using stairs, and recycling, but were less likely to take sustainability classes or participate in campus sustainability activities.

Students were asked about the sustainability attitudes and behaviors of groups that may provide social norms for evaluating their behaviors. Attitudes were measured on a five- 
Table 2: Attitudes toward Sustainability (Percent positive).

\begin{tabular}{|l|c|}
\hline \multicolumn{2}{|l|}{ What is the impact of sustainability on these aspects of your life? } \\
\hline Life satisfaction & $77 \%$ \\
\hline Your career & $67 \%$ \\
\hline Your health \& well-being & $94 \%$ \\
\hline Your friendships & $41 \%$ \\
\hline What is the impact of sustainability on our society and world? \\
\hline Next generation & $91 \%$ \\
\hline Quality of local communities & $90 \%$ \\
\hline U.S. economy & $62 \%$ \\
\hline Natural environments & $90 \%$ \\
\hline Overall view of sustainability & $90 \%$ \\
\hline
\end{tabular}

Table 3: Sustainable Behaviors (Percent Usually or Always).

\begin{tabular}{|l|c|}
\hline Wash laundry only with full load & $94 \%$ \\
\hline Use stairs rather than elevators in library & $89 \%$ \\
\hline Recycle newspaper, glass or plastic bottles & $78 \%$ \\
\hline Consume beverages in reusable bottles & $67 \%$ \\
\hline Use both sides of paper when printing & $63 \%$ \\
\hline Conserve water by taking shorter showers & $26 \%$ \\
\hline Use reusable bags when shopping & $24 \%$ \\
\hline Take a class about sustainability & $17 \%$ \\
\hline Buy organic or local vegetables & $16 \%$ \\
\hline Participate in campus sustainability activities & $8 \%$ \\
\hline
\end{tabular}

point scale from very negative to very positive. The results on Table 4 present the sum of positive and very positive attitudes ( 4 or 5 on the scale). The frequency of sustainable behaviors was measured on a five-point scale from never to always. The results on Table 4 present the sum of usually and always (4 or 5 on the scale). Table 4 also contains the correlations of these social norm ratings with the students' sustainability attitudes and behaviors.

The results show that the majority of the students' social groups had positive attitudes toward sustainability and over half of them frequently engaged in sustainable behaviors. The attitudes of friends and family were significantly related to both sustainability attitudes and behaviors. The behaviors of friends, peers, and professors were significantly related to both sustainability attitudes and behaviors. In general, friends
Table 4: Social Norms

\begin{tabular}{|c|c|c|c|}
\hline $\begin{array}{l}\text { How do the following groups view } \\
\text { sustainable practices? }\end{array}$ & $\begin{array}{l}\text { Percent } \\
\text { Positive }\end{array}$ & Attitude & $\begin{array}{l}\text { Behavior } \\
\text { Correlation }\end{array}$ \\
\hline Friends & $71 \%$ & $.27^{*}$ & $.31^{* *}$ \\
\hline Family & $70 \%$ & $.30 * *$ & $.29^{* *}$ \\
\hline Peers & $72 \%$ & $.25^{*}$ & .16 \\
\hline Professors & $75 \%$ & .15 & .15 \\
\hline $\begin{array}{l}\text { How often do the following groups } \\
\text { engage in sustainable practices? }\end{array}$ & $\begin{array}{c}\text { Percent } \\
\text { Frequency }\end{array}$ & Attitude & $\begin{array}{l}\text { Behavior } \\
\text { Correlation }\end{array}$ \\
\hline Friends & $61 \%$ & $.24^{*}$ & $.36^{* *}$ \\
\hline Family & $71 \%$ & .11 & .13 \\
\hline Peers & $52 \%$ & $.24 *$ & $.27^{* *}$ \\
\hline Professors & $55 \%$ & $.21^{*}$ & $.27^{* *}$ \\
\hline
\end{tabular}

$* p<.05 \quad * * p<.01$

were the most important social norm group and sustainability behaviors were more strongly related to social norms than attitudes. It is interesting to note that it is the sustainability behaviors of professors, and not their attitudes, that had a significant impact on student attitudes and behaviors.

Background information about the students allowed for an analysis of the effects of being at Cal Poly on sustainability attitudes and behaviors. It should be noted that because this sample was collected in the spring quarter, all of the participants had been exposed to the Cal Poly educational experience. There were no significant differences related to major or gender.

Although upperclassmen had more sustainability knowledge, attitudes, and behaviors, only the difference in sustainability behaviors was significant and it was not very large.

\section{Conclusions}

This research presents an assessment of the sustainability knowledge, attitudes, and behaviors of Cal Poly students. Students recognized the environmental aspects of sustainability, but often did not acknowledge the economic and social aspects of sustainability. They had positive attitudes toward sustainability and believed our society's transition to a sustainable future will be good for society, but they were less certain of its benefits to their life and careers. The students performed many environmentally responsible activities, but few were taking classes on sustainability or engaging in campus sustainability activities. The norms of the people in the students' lives were positive, but positive attitudes were more prevalent than positive behaviors. The attitudes and behaviors of their friends had a significant impact on students' willingness to engage in sustainable behaviors. 
There were few differences among students related to major or class level. This is a problem, because if Cal Poly's sustainability education were having a positive effect on students, then there should be a more substantial effect due to class level. (The lack of differences at class levels may be due to the fact that the only widespread sustainability education program on campus is aimed at freshmen in the dorms.) Cal Poly needs to do a better job showing students how sustainability will have a positive impact on their careers and on the economy. Students view their professors as having a positive attitude about sustainability, but demonstrating mixed enactment of sustainable behaviors. However, it is faculty behavior, and not attitudes, that had a significant impact on students' attitudes and behaviors.

The University environment provides an important setting for promoting sustainable behaviors. Psychological research on sustainability shows that one of the most important predictors of sustainable behaviors is other sustainable behavior (Gifford, 2007). Once people get in the habit of performing some sustainable behaviors, it is easier to persuade them to perform more sustainable behaviors. Moreover, their sustainable behaviors encourage others through the influence of social norms. The University has the opportunity to promote sustainable behaviors and expand the impact of those efforts through the effects of social norms.

University sustainability programs need to be assessed in order to demonstrate their effectiveness and provide feedback to improve the programs. Cal Poly has only begun to evaluate its sustainability educational experience and its effects on students' knowledge, attitudes and behaviors. The assessment system is still under development. Although measures of sustainability knowledge and the ability to think critically about sustainability issues are important, assessment approaches should not overlook the importance of sustainability attitudes and behaviors. We want our students to be knowledgeable about sustainability, but a successful University sustainability program must also result in students' willingness to act in a sustainable manner.

\section{References}

Ajzen, I. 1991. The theory of planned behavior. In Organizational Behavior and Human Decision Processes \#50; 179-211.

Cal Poly (2013). Sustainability. Retrieved at <www.sustainability.calpoly.edu>

Cialdini, R., Kallgren, C. \& Reno, R. 1991. A focus theory of normative conduct: $A$ theoretical refinement and reevaluation of the role of norms in human behavior. In Advances in Experimental Social Psychology \#24; 201-234.

Gifford, R. 2007. Environmental Psychology. 4th edition. Colville WA: Optimal Books.
Nickerson, R. 2002. Psychology and environmental change. Mahwah, New Jersey: Lawrence Erlbaum Associates, Inc.

Porritt, J. 2005. Capitalism as if the World Matters. Oxford: Earthscan Publications.

UN Commission on Environment and Development. 1987. Our Common Future. Oxford paperbacks. 